\title{
High-Performing Windowfarm Hydroponic System: Transcriptomes of Fresh Produce and Microbial Communities in Response to Beneficial Bacterial Treatment
}

\author{
Seungjun Lee, ${ }^{1}$ Ruisheng An, ${ }^{2}$ Parwinder Grewal, ${ }^{2}$ Zhongtang $\mathrm{Yu},{ }^{1,3}$ Zuzana Borherova, ${ }^{4}$ and \\ Jiyoung Lee ${ }^{1,5,6}$ \\ ${ }^{1}$ Environmental Sciences Graduate Program, The Ohio State University, Columbus, U.S.A.; ${ }^{2}$ Department of Entomology and \\ Plant Pathology, University of Tennessee, Knoxville, U.S.A.; ${ }^{3}$ Department of Animal Sciences, ${ }^{4}$ Department of Civil, \\ Environmental and Geodetic Engineering, ${ }^{5}$ Department of Food Science and Technology, and ${ }^{6}$ College of Public Health, \\ Division of Environmental Health Sciences, The Ohio State University
}

Accepted 19 November 2016.

\begin{abstract}
Beneficial microorganisms play an important role in enhancing plant health, especially by promoting resistance to plant pathogen infection. The purpose of this study was to gain an understanding of such protection by i) examining the responses of fresh produce (lettuce) to beneficial treatments in their transcriptomes, ii) comparing biological (bacteria, fungi, and oomycete) communities and their diversity when treated with Pseudomonas chlororaphis (beneficial bacterium) in windowfarm hydroponic systems, and iii) identifying the microorganisms in root areas and water. $P$. chlororaphis treatment was for increasing plant growth and fighting for Pythium ultimum infection. In addition, two more treatments were conducted: i) adding supporting media for increasing bacterial colonizing areas around roots and ii) $\mathrm{UV}$ irradiation in water for controlling nuisance biofilm buildup. Changes in gene regulation and expression in lettuce in response to these treatments were investigated. Comparisons of microbial profiles among the treatments and microbial identification were conducted using samples of supporting media (around roots) and water. The results demonstrated that i) $P$. chlororaphis enhanced lettuce growth, ii) $\boldsymbol{P}$. chlororaphis-treated lettuce showed dominantly expressed genes for membrane, catalytic activity, cellular process, and metabolic process categories, iii) $P$. chlororaphis treatment induced genes related to growth promotion and defense pathways, and iv) the microbial community of the root area was affected significantly by $\boldsymbol{P}$. chlororaphis treatment and microbial diversity in water was significantly changed by UV irradiation. This study provided insight into how beneficial treatments affects the fresh produce growth in root areas and water in a vertical hydroponic system.
\end{abstract}

Due to the development of new materials, tools, and equipment, hydroponic systems have been applied widely in diverse disciplines, including research, agriculture, horticulture, education, and personal gardening (Resh 2013). Because of their many

Corresponding author: J. Lee; E-mail: lee.3598@osu.edu

*The $\boldsymbol{e}$-Xtra logo stands for "electronic extra" and indicates that two supplementary figures are published online.

@ 2016 The American Phytopathological Society advantages (e.g., reuse of water and nutrients, ease of environmental control, and prevention of soil-borne diseases and pests), hydroponic systems are attractive alternatives for cultivating various crops (Jones 1997). However, hydroponic systems are prone to microbial contaminants that can rapidly spread through the water circulation systems and contaminate the entire crop production (Koseki et al. 2011; Lee et al. 2015). Due to the high concentrations of nutrients in hydroponic systems, plant pathogens can grow rapidly and may cause severe crop losses (Khan et al. 2003). Root rot infection is a significant and common problem that is often caused by fungal, bacterial, or oomycete pathogens (Nonomura et al. 2003). Consequently, many past studies have focused on preventing plant-pathogen infection or developing remedial agents for hydroponic conditions. For instance, a slow filtration system was developed to eliminate $P h y$ tophthora cinnamomi and an oxygen treatment was developed to control Pythium root rot (Chérif et al. 1997; van Os et al. 1999).

Biological control using beneficial bacteria offers several advantages, such as suppressing the growth of plant pathogens by producing one or both antipathogenic or siderophore substances and enhancing nutrient bioavailability (Pii et al. 2015; Walker et al. 1998). For example, Azospirillum brasilense treatment can trigger gene expression of iron uptake machinery in cucumber (Pii et al. 2016b). The treatments create a hostile environment for pathogens, promoting crop growth, and improving yields (Zheng et al. 2000). We have previously reported that the introduction of Pseudomonas chlororaphis into a windowfarm hydroponic system improved the quality and quantity of lettuce and reduced the crop damage caused by Pythium ultimum infection (Lee et al. 2015). Periodic UV irradiation was also efficient in reducing nuisance biofilm buildup while maintaining the optimal levels of beneficial effects of the $P$. chlororaphis in a hydroponic system (Lee et al. 2015). Despite multiple studies over several decades, it was difficult to determine exactly how deliberate bacterial treatments affected plant growth and development (Gul et al. 2012; Peer and Schippers 1989; Schönwitz and Ziegler 1986). Thus, in this study, transcriptomic analysis was conducted to gain information on the expression of genes associated with plant growth, metabolic pathways, immune system responses, stress mechanisms, and protective functions against plant pathogens. Also, there is still a dearth of information about the effect of treatment with beneficial bacteria on microflora and microbial ecology in the rhizosphere. 
The objective of the present study was to investigate the interaction by which $P$. chlororaphis promotes plant growth and protects plants from Pythium ultimum infection. It was performed with or without inoculation of $P$. chlororaphis, with or without UV irradiation in the water reservoir, and with and without adding beads to the supporting media (Figs. 1 and 2). We investigated the transcriptomic responses of plants upon interaction with $P$. chlororaphis and UV treatment in vertical hydroponic systems. Furthermore, we examined the treatment effects on bacterial and fungal (fungi and fungus-like oomycetes [kingdom Chromalveolata]) diversity and communities in the root area and water in hydroponic systems. This is the first study designed to help clarify some of the interactions between microorganisms and plants and to demystify microbial diversity and community structure in vertical hydroponic systems.

\section{RESULTS}

\section{Crop productivity.}

After 10 weeks, the length (from root to top) and weight of the lettuce were measured to determine productivity and the data were compared among the eight different treatment groups (Fig. 3). P. chlororaphis treatment significantly promoted lettuce development, including root hair, number of leaves, and color of leaves. Compared with the untreated groups, the mean length and weight of the $P$. chlororaphis treated groups were longer and heavier $(P<0.05)$. The length and weight of lettuce were not affected $(P>0.05)$ by the bead addition or the UV irradiation in the water reservoir.

\section{Transcriptomic analysis of fresh lettuce.}

The effect of $P$. chlororaphis on gene expression in lettuce was examined using transcriptomic analysis. After raw reads and filtering and quality checks, about 67.70 million 100-bp reads for the control group and 62.01 million 100-bp reads for the treated group were acquired. Gene ontology (GO) enrichment analysis was conducted to assort the gene function. Based on sequence homology, 29,555 sequences were categorized into
103 functional groups including three domains: i) cellular component, ii) molecular function, and ii) biological process (Supplementary Fig. S1). In each of these domains, the dominance of the expressed genes, including up- and downregulated genes, belonged to the following functional categories: membrane (18.6\% upregulated [221] and $16.4 \%$ downregulated [150]), catalytic activity (17.3\% upregulated [202] and $14.4 \%$ downregulated [164]), cellular process $(12.5 \%$ upregulated [281] and $11.9 \%$ downregulated [220]), and metabolic process (11.4\% upregulated [256] and 10.4\% downregulated [13.3]).

Among the expressed genes, key genes were selected based on statistical analysis using a $P$ value of less than 0.001 (the absolute value of fold change [treated plant/control plant] $\geq+3$ or $\leq-3$ ) and $P$ value of the Bonferroni correction less than, or equal to $2.21 \times$ $10^{-8}$ (Table 1). Among the selected genes, $29 \%$ are predicted to be related to cell defense and rescue, $21 \%$ to transcription, $13 \%$ to transport facilitation, $12 \%$ to response to stress, $10 \%$ to metabolism, $5 \%$ to systemic regulation or interaction with cellular environment, $4 \%$ to development, $3 \%$ to cellular communication or signal transduction, and $1 \%$ to energy and to biogenesis (Table 1). In the present research, several genes related to defense response, response to stress, and plant growth were selected to examine the beneficial effects of $P$. chlororaphis on lettuce in the hydroponic system: i) cell defense and rescue-cytochrome p450, tify $6 \mathrm{~b}$ (jasmonic acid biosynthesis), and several protein genes induced by auxin, ethylene, and wounding; ii) response to stress-inositol3-phosphate synthase, peroxisomal-2-hydroxy-acid oxidase, rubisco subunit-binding protein, nodulin family protein, conserved hypothetical protein, and oxoglutarate 3-dioxygenase; and iii) growth-inositol-3-phosphate synthase, peroxidase, cytochrome p450 family protein, embryo sac development, late embryogenesis abundant protein, nodulin-related protein, early nodulin-like protein, gibberellin-regulated protein, and auxin response factor 19. Even though UV irradiation slightly altered the expression of a few genes in lettuce, the $P$. chlororaphis treatment had a significant effect on gene expression. In the groups treated with both $P$. chlororaphis and UV irradiation, the genes involved in both defense response and metabolic process were the most induced.
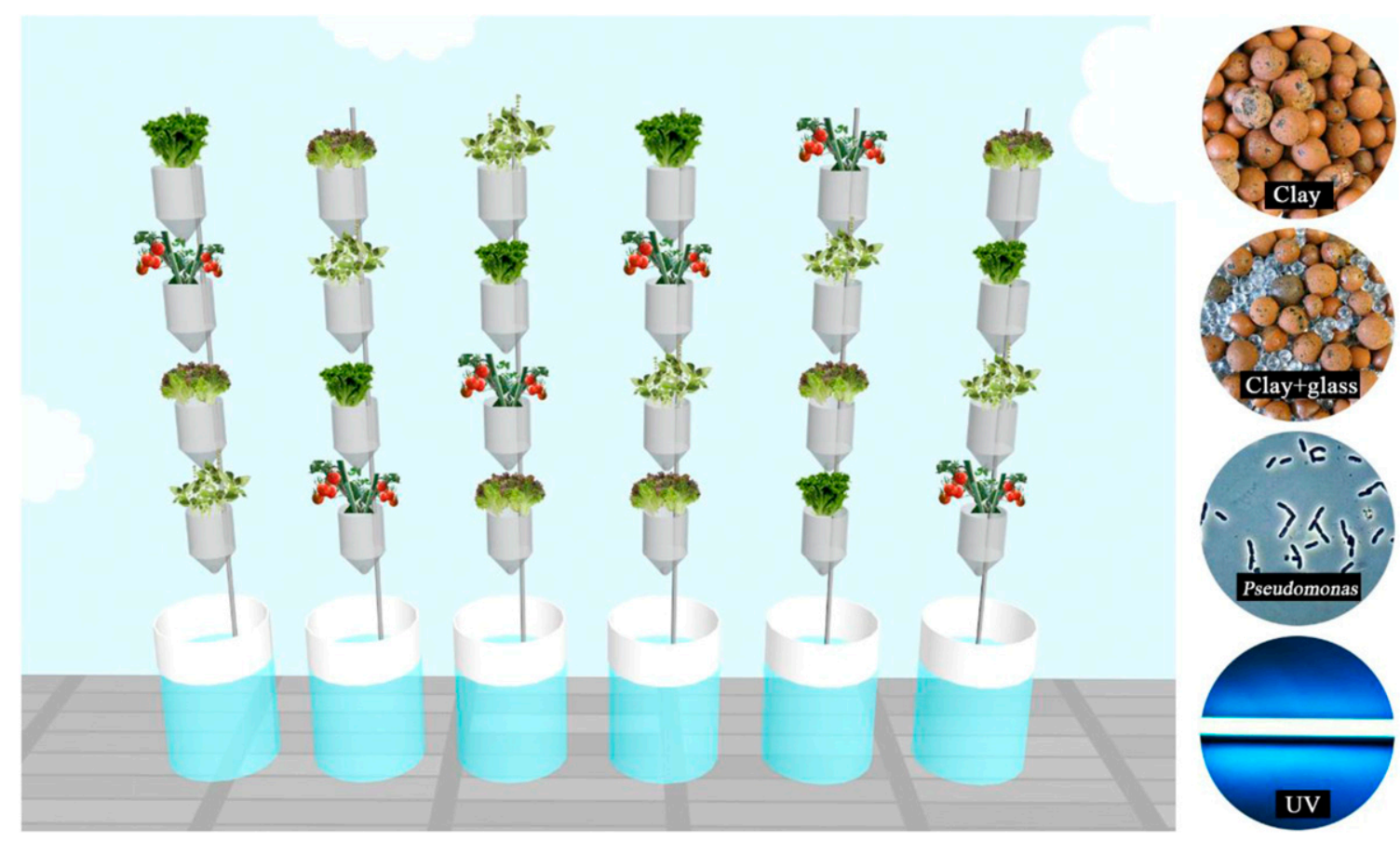

Fig. 1. Schematic diagram of the windowfarm hydroponic systems. Pseudomonas $=$ inoculation of $P$. chlororaphis around roots; UV $=\mathrm{UV}$ irradiation in water reservoirs for 5 min every week; Clay = supporting media with clay pellets only; Clay + glass = additional glass beads were added to clay pellets (1:1 ratio). 


\section{Bacterial and fungal diversity.}

Denaturing gradient-gel electrophoresis (DGGE) banding patterns of the bacterial community from the supporting media and water samples and the 34 bands identified for bacterial taxonomy. The indices of bacterial and fungal diversity obtained from the polymerase chain reaction (PCR)-DGGE banding profiles are shown in Table 2. The bacterial diversity around the root and in the water was not significantly different between the clay pellet groups and the mixture (clay pellet + beads) groups However, $P$. chlororaphis treatments significantly $(P<0.05)$ affected bacterial community richness, evenness, and the ShannonWiener diversity index around the root area and partially affected the bacterial community in the water. Even though UV irradiation did not affect bacterial diversity around the root, bacterial diversity in the water was significantly different between the nonUV and the UV-irradiation groups.

The DGGE banding pattern of the fungal community from the supporting media and water samples and the 29 bands identified for fungal taxonomy. Neither the supporting media nor the UV irradiation of the water reservoir significantly affected fungal diversity around the lettuce root $(P>0.05)$. However, fungal richness, evenness, and the Shannon-Wiener index were significantly different $(P<0.05)$ between the non- $P$. chlororaphis treated and the $P$. chlororaphis-treated groups. UV irradiation also significantly affected the above diversity measurements of the fungal communities in the water reservoir, though, as previously stated, it did not have an effect on the fungal diversity around roots.

Overall, the $P$. chlororaphis treatment slightly affected bacterial and fungal diversity. These data show that $P$. chlororaphis treatment influenced both bacterial and fungal diversity around the root area ( $P$. chlororaphis decreased the bacterial and fungal diversity [index] around the root area) and that UV irradiation affected bacterial and fungal diversity only in the circulating water (UV irradiation decreased the bacterial and fungal diversity [index] in the circulating water).

\section{Bacterial and fungal community structure.}

DGGE band patterns were analyzed for bacterial and fungal community structure in each group. The similarities of community in the root area among the different groups are summarized in Figure 4 and Supplementary Figure S2, in the form of a bandcomparison dendrogram. The samples were not tightly clustered (similarity $<85 \%$ ) based on the bead or UV irradiation. $P$. chlororaphis treatment and UV irradiation affected the development of the bacterial and fungal community structure around the root area, while the similarity of the UV groups and the Mixture + UV groups and the similarity of the $P$. chlororaphis $+\mathrm{UV}$ groups and the Mixture $+P$. chlororaphis $+\mathrm{UV}$ groups was above $90 \%$.

The similarity of bacterial band patterns in the water samples was $94 \%$ between the groups treated with $P$. chlororaphis and groups treated with the mixture and $P$. chlororaphis (Fig. 5A). The dendrogram of the banding pattern analysis shows that the bead treatment and the UV irradiation in the water reservoirs slightly changed the formation of bacterial community in the water (similarity $<85 \%$ ). The similarity of fungal community between the $P$. chlororaphis-treated groups with UV irradiation and the groups treated with mixture, UV irradiation, and P. chlororaphis was $95 \%$ (Fig. 5B). The dendrogram of the

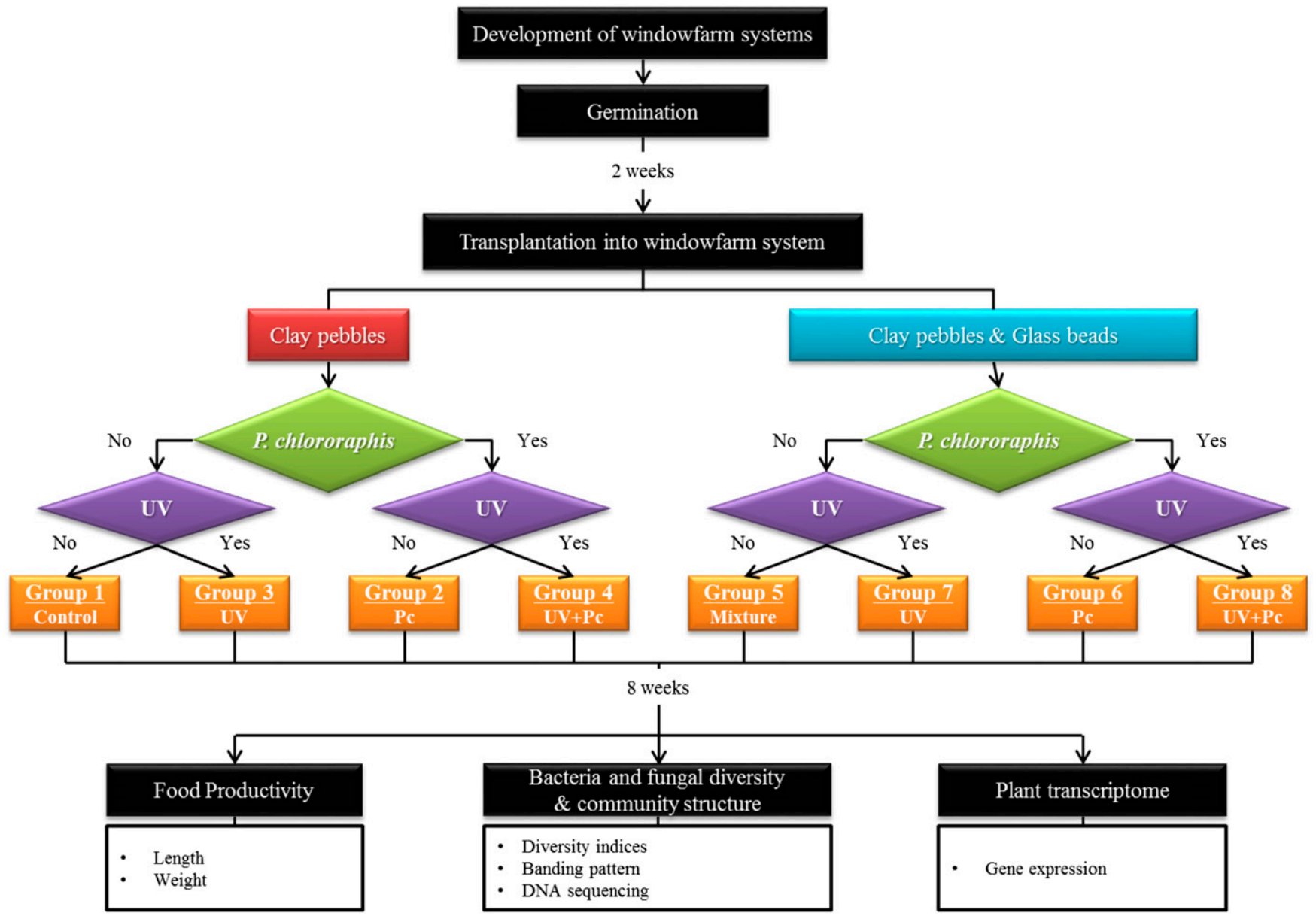

Fig. 2. Flowchart of the study design. Three different treatments (Pseudomonas chlororaphis inoculation, UV irradiation, and beads) were used. Each group had 24 replicates. 
banding pattern analysis shows that $P$. chlororaphis treatment and UV irradiation in the water reservoirs affected the development of fungal communities in the water. The banding profiles of the water samples also show that different usage of supporting media (clay-pebble groups and mixture-treated groups) caused low similarity $(<90 \%)$.

\section{Bacterial and fungal identification.}

From bacterial and fungal DGGE gels, 82 and 80 bands, respectively, were directly selected and the resulting sequences were analyzed by comparison with the most closely related bacterial $16 \mathrm{~S}$ rRNA or fungal $18 \mathrm{~S}$ rRNA sequences in the National Center for Biotechnology Information (NCBI) database. From the excised bands, 34 bacterial and 29 fungal sequences were obtained, and these sequences showed high sequence similarity $(\geq 95 \%)$ with the reference sequences (Table 3 ). From the root areas and circulating water, various species of bacteria and fungi were identified by plant growth-promoting rhizobacteria (PGPR), including four species of bacteria (Variovorax paradoxus, $P$. fluorescens, $P$. thivervalensis, and $P$. brassicacearum)
A

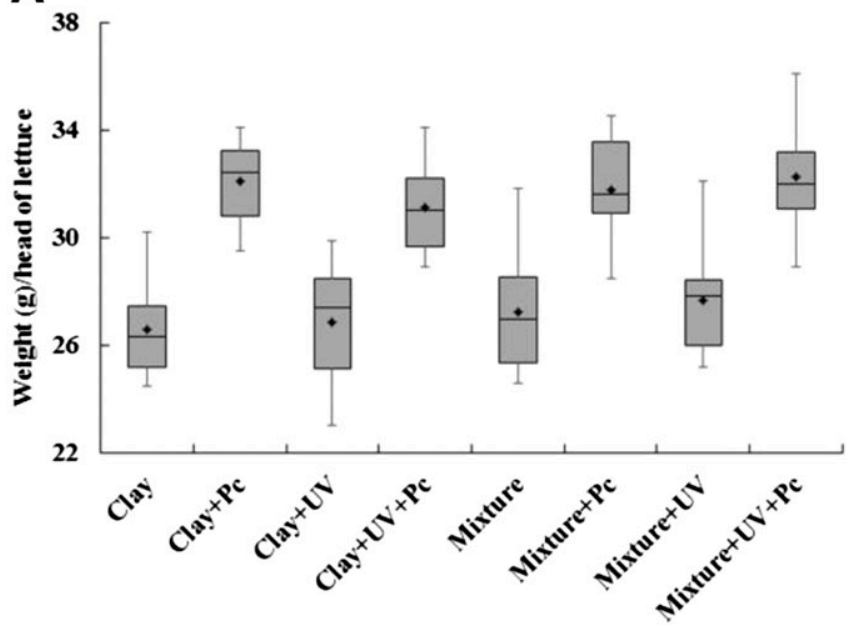

B

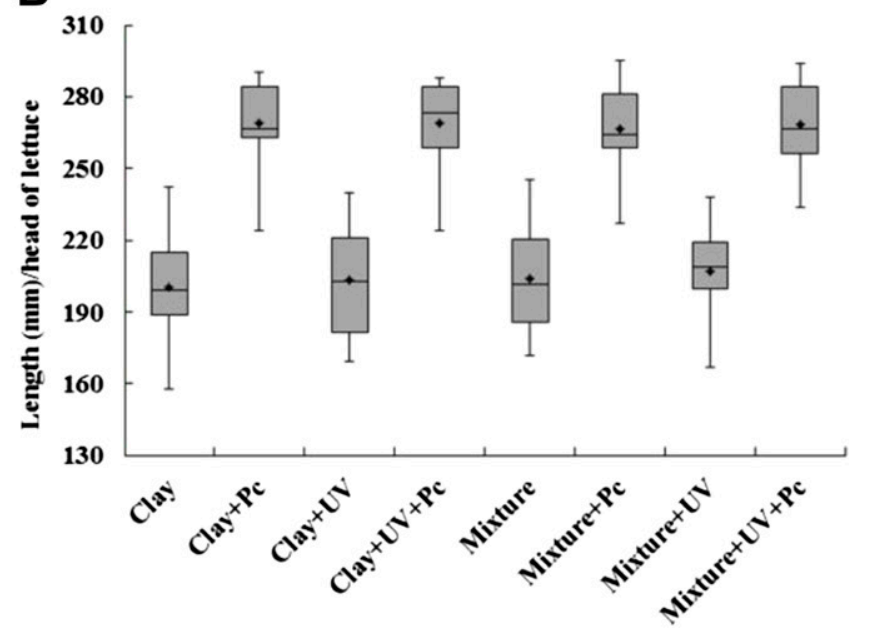

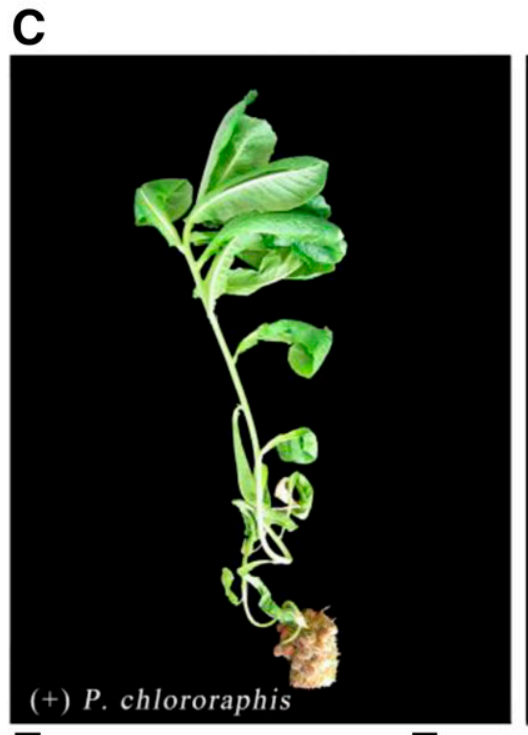

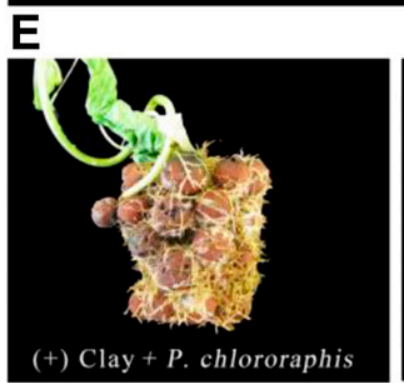

$\mathbf{F}$
D
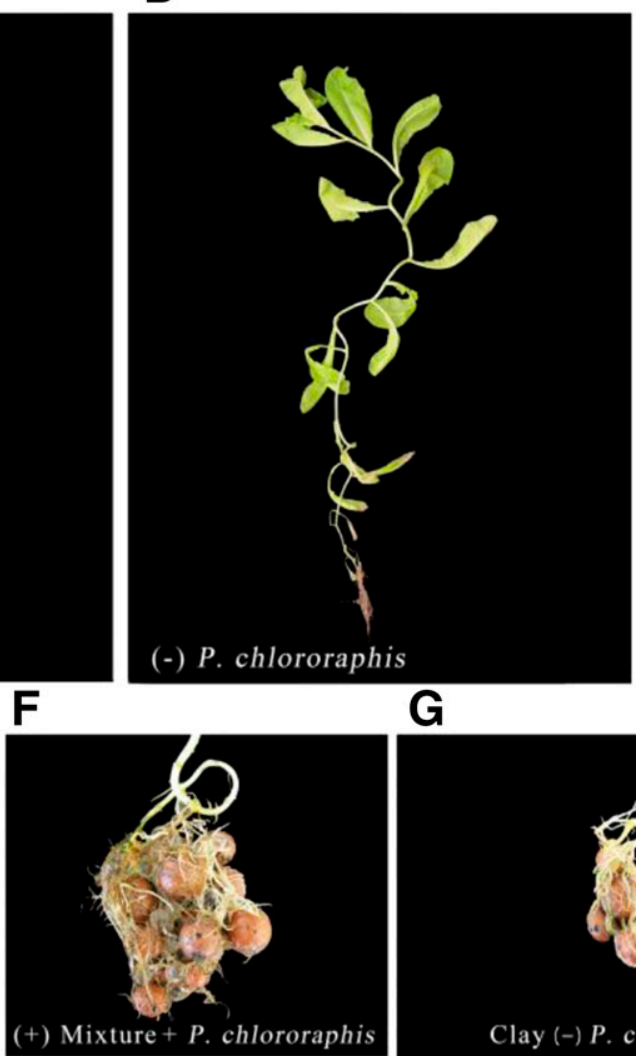

G

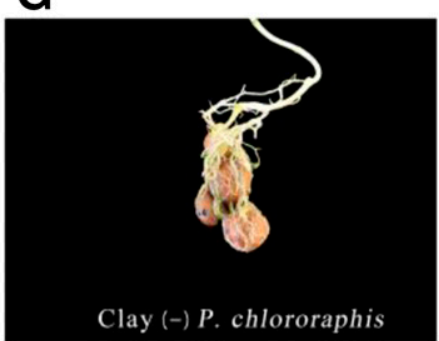

Fig. 3. Crop productivity measured by A, weight (grams per head) and $\mathbf{B}$, length (millimeters per head) of lettuce after 10 weeks. Box plot shows the means and medians of weight and length. The length of each box shows the interquartile range and $50 \%$ of cases of the variable. The line and the dot in the box indicate the means and the medians, respectively, while extended lines from the box showing maximum and minimum values of each group. Images show the appearance of leaves and roots of $P$. chlororaphis-treated lettuce to non-P. chlororaphis treated lettuce; C, . chlororaphis-treated lettuce root with clay pellets; D, non- $P$. chlororaphis treated lettuce root with clay pellets; $\mathbf{E}, P$. chlororaphis-treated lettuce root with clay pellets; $\mathbf{F}, P$. chlororaphis-treated lettuce root with clay pellets and glass beads; $\mathbf{G}$, root of non $-P$. chlororaphis treated lettuce with clay pellets. Clay $=$ clay pellet only; Mixture $=$ clay pellets and glass beads $(1: 1$ ratio). 
Table 1. Fold-change ratios of up- and downregulated genes responsive to plant growth-promoting rhizobacteria ${ }^{\mathrm{a}}$

\begin{tabular}{|c|c|c|c|c|c|}
\hline \multirow[b]{2}{*}{ Functional categories annotation } & \multicolumn{2}{|c|}{ Fold-change ratio } & \multirow[b]{2}{*}{ Functional categories annotation } & \multicolumn{2}{|c|}{ Fold-change ratio } \\
\hline & UV & $\mathbf{U V}+\mathbf{P c}$ & & UV & $\mathbf{U V}+\mathbf{P c}$ \\
\hline Biogenesis of cellular component & & & Response to stress & & \\
\hline Germin-like protein 5-1 & 1.0 & -2.9 & 9-cis-epoxy-carotenoid dioxygenase & 2.1 & 3.3 \\
\hline Cell defense and rescue & & & Conserved hypothetical protein & 1.0 & 3.8 \\
\hline Allene oxide cyclase chloroplastic & 1.0 & 12.4 & Glutamine synthetase leaf chloroplastic & 1.0 & 5.1 \\
\hline Catalase & 1.0 & 423.4 & Inositol-3-phosphate synthase & 1.0 & 88888.0 \\
\hline Cytochrome p450 & 1.0 & 3.5 & Major latex & 1.0 & 5.0 \\
\hline Cytochrome p 450 family protein & -2.0 & 4.1 & Nodulin family protein & -2.5 & 3.8 \\
\hline Disease resistance family protein lrr family & 1.0 & 2.3 & Oxoglutarate 3-dioxygenase & 1.0 & 24.2 \\
\hline Glutaredoxin family protein & 2.1 & 17.3 & Peroxisomal-2-hydroxy-acid oxidase & 1.0 & 88888.0 \\
\hline Glutathione s-transferase family protein & -2.1 & 2.4 & Phospholipase $\mathrm{d}$ family protein & 1.0 & 87.2 \\
\hline Glutathione s-transferase-like & 2.1 & 4.4 & Reticuline oxidase & 1.0 & 88888.0 \\
\hline Heat shock 70 kda protein 2 & 1.0 & 2.1 & Rubisco large subunit-binding protein & 1.0 & 7.1 \\
\hline Heat shock protein 83 & 1.0 & 2.7 & Transcription & & \\
\hline Heat shock cognate 70 kda protein isoform 1 & 1.0 & 3.6 & Chaperone protein dnaj chloroplastic & 1.0 & -2.6 \\
\hline Jasmonic pathway: & & & Ethylene-responsive transcription factor 1 & 1.0 & 7.0 \\
\hline Pistil-specific extensin-like protein & -3.2 & 5.9 & Ethylene-responsive transcription factor 5 & -3.4 & 2.9 \\
\hline Protein tify $6 \mathrm{~b}$-like isoform $\mathrm{x} 3$ & -2.1 & 3.2 & Ethylene-responsive transcription factor 13 & -3.3 & -2.2 \\
\hline Protein tify $6 \mathrm{~b}$ & 1.0 & 3.2 & Ethylene-responsive transcription factor rap2-4 & 1.0 & 2.1 \\
\hline Peroxidase & -2.5 & 3.5 & Ethylene-responsive transcription factor erf017 & -2.4 & 7.3 \\
\hline Phenylalanine ammonia-lyase & 2.1 & 4.0 & Myb-like 102 & 1.0 & 3.0 \\
\hline Proline-rich & 3.1 & 2.2 & Ring-h2 finger protein at $121 \mathrm{a}$ & 1.0 & 2.5 \\
\hline Proline-rich receptor-like protein kinase perk1-like isoform 2 & -7.0 & 2.6 & Ring-h2 finger protein at13 & -2.1 & 3.1 \\
\hline Several proteins induced by auxin, ethylene, and wounding: & & & Ring-h2 finger protein at18 & 1.0 & 3.4 \\
\hline Auxin-induced in root cultures protein 12 & 1.0 & 12.0 & Ring-h2 finger protein at154 & 1.0 & -3.5 \\
\hline Auxin response factor 19 & 1.0 & 4.8 & Transcription factor myblr1 & 6.0 & -2.3 \\
\hline Ethylene-responsive transcription factor erf054 & 1.0 & 2.1 & Transcription factor myb44 & 1.0 & -3.6 \\
\hline Ethylene-responsive transcription factor rap2-4 & 1.0 & 2.1 & Transcription factor myb44 & 1.0 & -3.2 \\
\hline Ethylene-responsive transcription factor 1 & 1.0 & 7.0 & Transcription factor myb113 & 1.0 & 10.0 \\
\hline Ethylene-responsive transcription factor 5 & 1.0 & 2.9 & Wrky transcription factor 11 & -2.3 & 2.6 \\
\hline Wound-induced protein 1 & 1.0 & 88888.0 & Wrky transcription factor 33 & -3.7 & 5.5 \\
\hline Zinc finger ccch domain-containing protein 29 & 2.0 & 2.6 & Wrky transcription factor 57 & 1.0 & 2.1 \\
\hline Zinc finger protein constans & -2.2 & 4.3 & Wrky transcription factor 70 & 1.0 & -2.4 \\
\hline Cellular communication or signal transduction & & & Transport facilitation & & \\
\hline Cbl-interacting protein kinase 25 & 1.0 & -4.3 & Boron transporter 4 & 1.0 & 16.2 \\
\hline Cbl-interacting serine threonine-protein kinase 6 & 2.4 & 2.8 & Copper transporter 5 & 1.0 & 9.8 \\
\hline Leucine-rich repeat family protein & 1.0 & 12.8 & High affinity nitrate transporter & -2.6 & 2.9 \\
\hline Development & & & Inositol transporter 1 & 6.2 & 8.5 \\
\hline Early nodulin-like protein 2 & 1.0 & 13.0 & Lysine histidine transporter 1 & 1.0 & 3.3 \\
\hline Embryo sac development & 1.0 & 3.4 & Metal ion binding & 1.0 & 3.9 \\
\hline Late embryogenesis abundant protein lea5 & 1.0 & 5.8 & Nadh-plastoquinone oxidoreductase subunit 5 & 1.0 & 88888.0 \\
\hline Nodulin-related protein & 1.0 & 7.8 & Nitrate transporter & 1.0 & 4.2 \\
\hline Energy & & & Oligopeptide transporter 4 & 1.0 & -3.5 \\
\hline Nitrate reductase & 1.0 & 2.8 & Potassium transporter 8 & 1.0 & 2.2 \\
\hline Metabolism & & & Sodium-coupled neutral amino acid transporter 4 & 1.0 & 4.1 \\
\hline Alcohol dehydrogenase & 1.0 & 2.2 & Vacuolar iron transporter 1 & 1.0 & 2.6 \\
\hline Aldehyde dehydrogenase family 2 member & 1.0 & 2.4 & Systemic regulation or interaction with cellular environment & & \\
\hline Glycine dehydrogenase & -2.3 & 7.1 & & & \\
\hline Lipase 1 & -3.2 & -3.9 & 1-Aminocyclopropane-1-carboxylate synthase & 12.1 & 8.0 \\
\hline Nadh dehydrogenase & 1.0 & 9.7 & Auxin response factor 19 & 1.0 & 4.8 \\
\hline Quinone oxidoreductase & 1.0 & 2.5 & Auxin efflux carrier component 3 & 1.0 & 385.5 \\
\hline$S$-adenosylmethionine synthase 2 & -3.5 & 2.9 & Gibberellin-regulated protein & 1.0 & 3.4 \\
\hline UDP-glucose 6-dehydrogenase 1 & 1.0 & 3.7 & Gibberellin receptor gid lc & 2.1 & 4.4 \\
\hline Xyloglucan glycosyltransferase 4 & 2.4 & 2.2 & & & \\
\hline
\end{tabular}

${ }^{a}$ Comparisons between Pseudomonas chlororaphis-treated groups with UV irradiation (UV + Pc) and UV irradiation-treated (UV) groups compared with the control group (without UV irradiation and $P$. chlororaphis treatment). The technical limit of fold-change ratios is from -8888 to 8888 . 
Table 2. Diversity indices calculated from the denaturing gradient-gel electrophoresis (DGGE) banding profiles ${ }^{\mathrm{a}}$

\begin{tabular}{|c|c|c|c|c|c|c|c|}
\hline \multirow[b]{2}{*}{ No. } & \multirow[b]{2}{*}{ Supporting media ${ }^{b}$} & \multicolumn{3}{|c|}{ Bacteria } & \multicolumn{3}{|c|}{ Fungi } \\
\hline & & Richness (S) & $\begin{array}{c}\text { Shannon-Wiener } \\
\text { index }(\mathbf{H})\end{array}$ & $\begin{array}{l}\text { Evenness } \\
\text { index }(E)\end{array}$ & Richness (S) & $\begin{array}{c}\text { Shannon-Wiener } \\
\text { index }(\mathbf{H})\end{array}$ & $\begin{array}{l}\text { Evenness } \\
\text { index }(\mathbf{E})\end{array}$ \\
\hline 1 & Control & $24.8 \pm 2.7$ & $3.03 \pm 0.08$ & $0.95 \pm 0.02$ & $22.7 \pm 1.8$ & $3.43 \pm 0.03$ & $0.92 \pm 0.04$ \\
\hline 2 & $\mathrm{Pc}$ & $23.2 \pm 2.4$ & $2.82 \pm 0.17$ & $0.85 \pm 0.01$ & $19.4 \pm 1.6$ & $3.06 \pm 0.07$ & $0.86 \pm 0.01$ \\
\hline 3 & UV & $25.1 \pm 3.1$ & $3.10 \pm 0.21$ & $0.97 \pm 0.02$ & $22.1 \pm 2.0$ & $3.35 \pm 0.12$ & $0.92 \pm 0.03$ \\
\hline 4 & $\mathrm{Pc}+\mathrm{UV}$ & $22.8 \pm 2.0$ & $2.78 \pm 0.18$ & $0.84 \pm 0.03$ & $19.5 \pm 3.8$ & $3.05 \pm 0.03$ & $0.85 \pm 0.02$ \\
\hline 5 & Mixture & $24.9 \pm 2.2$ & $3.02 \pm 0.14$ & $0.94 \pm 0.03$ & $21.8 \pm 2.2$ & $3.30 \pm 0.20$ & $0.92 \pm 0.02$ \\
\hline 6 & Mixture+Pc & $22.0 \pm 2.6$ & $2.88 \pm 0.10$ & $0.87 \pm 0.02$ & $20.1 \pm 4.0$ & $3.04 \pm 0.09$ & $0.84 \pm 0.03$ \\
\hline 7 & Mixture+UV & $25.5 \pm 3.6$ & $3.04 \pm 0.24$ & $0.95 \pm 0.03$ & $22.9 \pm 1.9$ & $3.36 \pm 0.07$ & $0.92 \pm 0.01$ \\
\hline 8 & $\begin{array}{l}\text { Mixture+Pc+UV } \\
\text { Water samples }\end{array}$ & $23.1 \pm 2.5$ & $2.95 \pm 0.29$ & $0.86 \pm 0.02$ & $19.2 \pm 3.2$ & $3.05 \pm 0.15$ & $0.85 \pm 0.02$ \\
\hline 1 & Control & $26.4 \pm 4.1$ & $3.32 \pm 0.17$ & $0.99 \pm 0.01$ & $20.5 \pm 3.1$ & $2.84 \pm 0.07$ & $0.82 \pm 0.02$ \\
\hline 2 & $\mathrm{Pc}$ & $24.5 \pm 4.2$ & $3.16 \pm 0.20$ & $0.97 \pm 0.02$ & $19.7 \pm 2.0$ & $2.83 \pm 0.04$ & $0.82 \pm 0.01$ \\
\hline 3 & UV & $22.9 \pm 3.6$ & $2.96 \pm 0.15$ & $0.93 \pm 0.01$ & $15.1 \pm 2.8$ & $2.12 \pm 0.07$ & $0.76 \pm 0.02$ \\
\hline 4 & $\mathrm{Pc}+\mathrm{UV}$ & $22.4 \pm 3.2$ & $2.91 \pm 0.15$ & $0.93 \pm 0.03$ & $15.3 \pm 1.9$ & $2.10 \pm 0.04$ & $0.76 \pm 0.03$ \\
\hline 5 & Mixture & $26.7 \pm 2.9$ & $3.30 \pm 0.24$ & $0.98 \pm 0.02$ & $21.2 \pm 2.3$ & $2.85 \pm 0.15$ & $0.83 \pm 0.01$ \\
\hline 6 & Mixture+Pc & $24.8 \pm 3.1$ & $3.20 \pm 0.20$ & $0.97 \pm 0.02$ & $20.1 \pm 3.0$ & $2.80 \pm 0.08$ & $0.81 \pm 0.01$ \\
\hline 7 & Mixture+UV & $22.3 \pm 2.5$ & $2.92 \pm 0.18$ & $0.93 \pm 0.02$ & $16.2 \pm 1.8$ & $2.17 \pm 0.12$ & $0.77 \pm 0.02$ \\
\hline 8 & Mixture+Pc+UV & $21.9 \pm 3.3$ & $2.88 \pm 0.11$ & $0.93 \pm 0.01$ & $15.0 \pm 3.2$ & $2.12 \pm 0.04$ & $0.76 \pm 0.03$ \\
\hline
\end{tabular}

a Generated from DGGE fingerprints of microbial communities from supporting media samples. The comparison of diversity indices between each group was performed using an independent two sample $t$ test.

b $\mathrm{PC}=$ Pseudomonas chlororaphis inoculation in root area, UV $=\mathrm{UV}$ irradiation in water reservoirs for 5 min every week; Mixture $=$ clay pellets + glass beads (1:1 ratio).
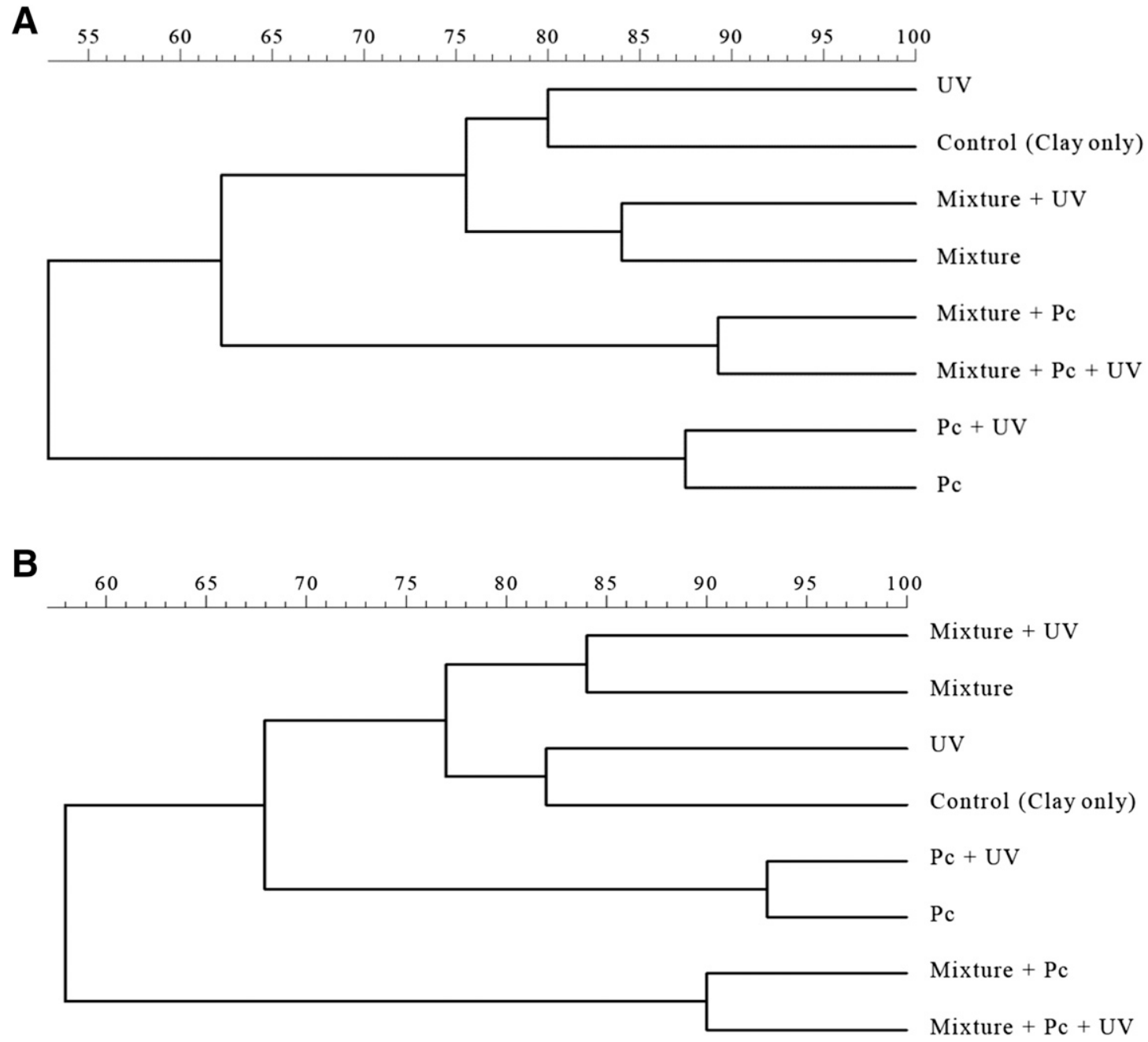

Fig. 4. Banding pattern analysis of $\mathbf{A}$, bacterial and $\mathbf{B}$, fungal communities around root area by band-search algorithm and band comparison among the different groups. UV = UV irradiation; Clay = clay pellets only; Mixture = clay pellets and glass beads; and Pc = P. cholororaphis treatment. 
and five species of fungi (Trichoderma harzianum, Trichoderma asperellum, Aureobasidium pullulans, Penicillium bilaiae, and Verticillium lecanii). Pathogenic plant bacteria and fungi or oomycetes were also identified: Acidovorax avenae, Rhizoctonia solani, Pythium spp. (Pythium ultimum, Pythium aphanidermatum, Pythium dissotocum), Fusarium spp. (F. merismoides, F. oxysporum, F. culmorum), Penicillium expansum, and Mucor piriformis.

\section{DISCUSSION}

\section{Lettuce productivity.}

PGPR have been widely studied to identify their effects on plant growth and development. PGPR may induce plant growth by several mechanisms: i) producing beneficial compounds, such as phytohormones and siderophores, ii) enhancing bioavailability of nutrients in soil, iii) regulating stress or defense mechanisms of plants, and iv) inhibiting growth of plant pathogens (Islam et al. 2014). However, there are limited studies showing the beneficial effects of PGPR in hydroponic systems. P. chlororaphis PCL1391 treatment of tomatoes was shown to protect against root rot caused by Fusarium oxysporum by making phenazine-1-carboxamide, which is a control agent for the fungal disease (Chin-A-Woeng et al. 2000; Pii et al. 2016b). Pseudomonas putida treatment increased cucumber yield and prevented fungal infections (Fusarium oxysporum) (Gül et al. 2013).
The previous and present studies revealed that UV irradiation in water reservoirs did not significantly impact the growth of lettuce (root hairs, length, or weight) while minimizing biofilm build up in the hydroponic systems (Lee et al. 2015). The addition of supporting media to the hydroponic systems did not significantly alter the productivity of lettuce (root hairs, length, or weight). However, introduction of $P$. chlororaphis into the hydroponic systems increased both the weight $(17 \%)$ and length $(30 \%)$ of lettuce. Also, the roots of the P. chlororaphistreated groups were more developed than the nontreated groups (Fig. 3). Our previous study (Lee et al. 2015) demonstrated similar results; PGPR-treated fresh produce in the hydroponic system showed significantly enhanced crop quality (enhancement of color) and quantity (mass, length, and number of leaves per head) and reduced damage, such as withering and mortality of leaves or root rot, caused by the plant pathogen Pythium ultimum. These encouraging results from previous and current studies on plant growth and development led to the next step of transcriptome analysis of plants to see how plants respond to PGPR treatment. Furthermore, since PGPR play an important role in agriculture, especially in carbon and nitrogen cycling, formation of dissolved organic compounds, nutrient availability, and many other processes (Alegria Terrazas et al. 2016; Parray et al. 2016; Piromyou et al. 2011; Scagliola et al. 2016), it is worth further investigation to better understand the relationship between microbes and plants and ecological patterns
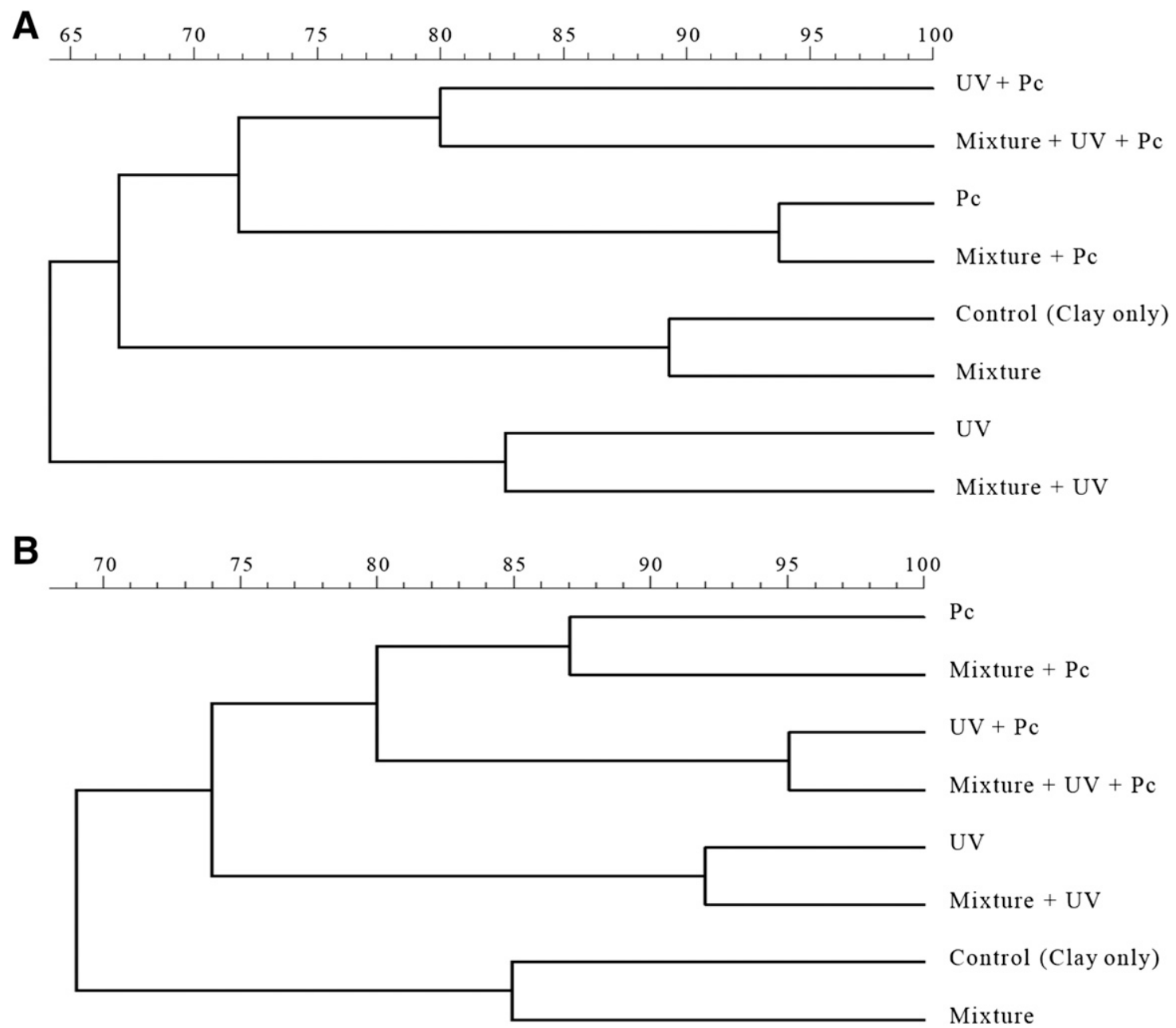

Fig. 5. Banding pattern analysis of $\mathbf{A}$, bacterial and $\mathbf{B}$, fungal community in water samples of the windowfarm system by band-search algorithm and band comparison among the different groups. UV $=\mathrm{UV}$ irradiation; Clay = clay pellets only; Mixture = clay pellets and glass beads; and Pc $=$ P. cholororaphis treatment. 
(e.g., general microbial communities, distribution, and microbial networks in hydroponic systems).

\section{Transcriptomes of the treated lettuce.}

In our previous study, when Pythium ultimum (plant pathogen) was spiked around the root area, $83 \%$ of the non-P. chlororaphis treated lettuce showed symptoms caused by Pythium ultimum, but $54 \%$ of the $P$. chlororaphis-treated lettuce had no detectable disease symptoms; the lettuce did not show any symptoms of root rot and withering or mortality of leaves (Lee et al. 2015). Based on our previous results, we wanted to focus on gene expression insights involved in responses to interactions between plants and PGPR through transcriptome profiling. Few studies provide transcriptomic information on plants with PGPR in hydroponic systems (Lakshmanan et al. 2013). P. fluorescens inoculation altered about 100 genes of Arabidopsis thaliana, including both up- and downregulation (Verhagen et al. 2004). Our transcriptomic results demonstrated that the defense responses and metabolic processes of lettuce were affected by $P$. chlororaphis treatment. Also, $P$. chlororaphis treatment led to increased expression of genes involved in responses to pathogens and external stresses and in certain metabolic activities (Table 1). Of particular interest in this study is the fact that $P$. chlororaphis upregulated the expression of the protein tify $6 \mathrm{~b}$ gene that is involved in the jasmonic acid biosynthesis pathway. The phytohormone jasmonic acid is a key signaling regulator of systemic immune response, plant stress responses, and development of plants (Choudhary and Johri 2009). Previous studies showed that jasmonic acid is also essential to healing wounds and to development of female organs, embryos, seed germination, root growth, glandular trichome formation, tubers, and leaves in tomatoes (Li et al. 2004; Wasternack et al. 2006). Park et al. (2002) also showed that jasmonic acid is a key factor associated with male sterility. This study thus presents an important finding: $P$. chlororaphis has a beneficial ability, i.e., induction of plant defense genes such as the jasmonic pathway.

In addition, the expression of several other genes was also affected by $P$. chlororaphis treatment. The nodulin family protein has been reported to regulate phosphorylation activity, signaling activity, stimulate transport activity, and promote resistance to environmental and osmotic stresses (Pii et al. 2012; Wallace et al. 1996). The leucine-rich repeat family proteins, which have multiple functions, have been identified to control genes resistant to a plant pathogen, structure of plant, and interactions between proteins (Jones and Jones 1997). Genes encoding the inositol3-phosphate synthase can enhance the germination and development of maize and soybeans (Hegeman et al. 2001). Some upregulated genes involved in development of plants were also found, including embryo sac development (pollen development), peroxidase (cell tissue), cytochrome p450 family protein (pollen formation), late embryogenesis abundant protein (seed development), nodulin-related protein and early nodulin-like protein (response to heat stress and root hair and phloem development), gibberellin-regulated protein (seed and floral development), and auxin response factor 19 (development) (Achard et al. 2004; Li et al. 2006, 2010; Narendra et al. 2006; Niewiadomski et al.

Table 3. Identification of bands obtained by polymerase chain reaction denaturing gradient-gel electrophoresis and the closest sequence match of known bacteria and fungi from other references

\begin{tabular}{|c|c|c|c|c|c|}
\hline \multirow[b]{2}{*}{ Identity $^{\mathbf{a}}$} & \multicolumn{2}{|c|}{ Bacteria } & \multicolumn{3}{|c|}{ Fungi and oomycetes } \\
\hline & Accession no. & Similarity $(\%)^{\mathbf{b}}$ & Identity & Accession no. & Similarity $(\%)$ \\
\hline Variovorax paradoxus & NR042434.1 & 97 & Rhizoctonia solani & GU062258.1 & 97 \\
\hline Variovorax boronicumulans & NR074654.1 & 97 & Phialophora richardsiae & AB364704.1 & 97 \\
\hline Simplicispira limi & NR043773.1 & 98 & Pythium ultimum & AB370103.1 & 99 \\
\hline Pseudomonas chlororaphis & NR074834.1 & 99 & Trichoderma harzianum & KP063130.1 & 95 \\
\hline Acidovorax avenae & NR042939.1 & 96 & Aureobasidium pullulans & DQ683019.1 & 98 \\
\hline Rhodanobacter spathiphylli & NR041588.1 & 98 & Pythium aphanidermatum & КС594034.1 & 99 \\
\hline Simplicispira psychrophila & NR028711.1 & 95 & Geomyces pannorum & КC008742.1 & 96 \\
\hline Variovorax defluvii & NR028712.1 & 95 & Gigaspora gigantea & AJ539238.1 & 95 \\
\hline Mycobacterium abscessus & NR109102.1 & 96 & Fusarium merismoides & AB586997.1 & 96 \\
\hline Giesbergeria sinuosa & NR102856.1 & 97 & Aspergillus flavus & KF309064.1 & 97 \\
\hline Mycobacterium fortuitum & NR035948.1 & 96 & Penicillium bilaiae & KC862266.1 & 95 \\
\hline Mycobacterium senegalense & NR074451.1 & 98 & Aureobasidium melanogenum & FJ150905.1 & 98 \\
\hline Pseudomonas fluorescens & NR025942.1 & 96 & Pythium dissotocum & AB355600.1 & 99 \\
\hline Pseudomonas asturiensis & NR041346.1 & 97 & Mucor plumbeus & JN205916.1 & 97 \\
\hline Phenylobacterium conjunctum & NR074591.1 & 97 & Engyodontium album & KC485425.1 & 95 \\
\hline Mycobacterium kumamotonense & NR104775.1 & 96 & Penicillium fagi & AF481124.1 & 98 \\
\hline Roseomonas riguiloci & NR042921.1 & 97 & Fusarium oxysporum & GU212653.1 & 99 \\
\hline Pedobacter metabolipauper & NR074427.1 & 95 & Penicillium expansum & KC169942.1 & 96 \\
\hline Acidovorax ebreus & NR041439.1 & 96 & Mucor piriformis & JN206030.1 & 97 \\
\hline Pedobacter westerhofensis & NR102835.1 & 99 & Phialophora verrucosa & KJ701013.1 & 95 \\
\hline Rhodoferax ferrireducens & NR108461.1 & 96 & Bullera crocea & GQ911539.1 & 97 \\
\hline Arthrobacter phenanthrenivorans & NR024946.1 & 95 & Verticillium lecanii & KF225042.1 & 97 \\
\hline Wolinella succinogenes & NR041963.1 & 96 & Cladosporium cladosporioides & FJ797613.1 & 98 \\
\hline Nocardia brasiliensis & NR074743.1 & 95 & Acremonium strictum & GU595023.1 & 95 \\
\hline Rhodococcus kunmingensis & NR044034.1 & 96 & Neocosmospora vasinfecta & GU213063.1 & 97 \\
\hline Mycobacterium hiberniae & NR026092.1 & 97 & Gigaspora rosea & AF004700.1 & 95 \\
\hline Pedobacter duraquae & NR109149.1 & 97 & Trichoderma asperellum & HM545081.1 & 95 \\
\hline Beijerinckia indica & NR042601.1 & 99 & Cladosporium herbarum & $\mathrm{AF} 222830.1$ & 96 \\
\hline Sulfurimonas paralvinellae & NR042602.1 & 95 & Fusarium culmorum & GU212653.1 & 99 \\
\hline Sulfurimonas autotrophica & NR074770.1 & 96 & & & \\
\hline Pseudomonas fragi & NR042603.1 & 96 & & & \\
\hline Arthrobacter arilaitensis & NR074608.1 & 97 & & & \\
\hline Pseudomonas brassicacearum & NR004554.1 & 95 & & & \\
\hline Pseudomonas thivervalensis & NR_024951.1 & 98 & & & \\
\hline
\end{tabular}

${ }^{a}$ Closest match to band sequence obtained by comparison with BLAST search. Numbers in parentheses indicate the GenBank accession number.

b Similarity is the ratio of identical sequence between the closest sequence from database entry and the band sequence, which was obtained after BLAST. 
2005; Shih et al. 2008; Wechter et al. 2008). Therefore, these upregulated genes, related to development, metabolism, and biogenesis by $P$. chlororaphis treatment, can promote the development and productivity of lettuce.

Several genes associated with external stress response were up-regulated, such as reticuline oxidase, 9-cis-epoxy-carotenoid dioxygenase, and conserved hypothetical protein (drought), cytochrome p450 and oxoglutarate 3-dioxygenase (biotic and abiotic stress), peroxisomal-2-hydroxy-acid oxidase (oxidation), phospholipase D family protein (multiple stress), glutamine synthetase leaf chloroplastic, rubisco large subunit-binding protein (heat and salt), and major latex (wound) (Bargmann and Munnik 2006; Demirevska-Kepova et al. 2005; Iuchi et al. 2000; Narusaka et al. 2004; Reumann et al. 2007). Therefore, members of these genes related to stress response will help to protect plants against an adverse external environment.

This novel transcriptomic study of lettuce demonstrated that introducing $P$. chlororaphis to hydroponic systems can upregulate a variety of genes related to defense response, response to stress, and plant growth. In addition, our transcriptomic study provides a better understanding of how beneficial bacteria cooperate with plants in areas such as plant growth, plant hormone regulation, and defense regulatory mechanisms.

\section{Bacterial and fungal diversity and community.}

The investigation of microbial diversity and structure is an important part of microbiology, because the information helps to understand the interaction between microorganisms and the environments (Yu et al. 2013). PCR-DGGE, which has been used to obtain information on both culturable and nonculturable microorganisms, is a suitable method for comparing microbial patterns under different conditions (Yu et al. 2013). Specifically, PCRDGGE analysis can be used to examine the effect of PGPR on microbial diversity and communities. Plants affect the development of the soil microbiome around their roots (Germida and Siciliano 2001; Pii et al. 2016a; Smalla et al. 2001). PGPR can also cause localized changes in a microbial community in a rhizosphere (Chin-A-Woeng et al. 2000). However, only a few studies investigated the microbial change in hydroponic systems. In hydroponic systems, microbial community change is especially vulnerable to external influences (Xiao et al. 2010). Hence, this study presents novel research focused on bacterial and fungal community structure in the supporting media and circulating water in a hydronic system.

In spite of treatments with either additional supporting media (beads), UV irradiation, or both in water reservoirs, which might have provided different environments around the root area for microbial growth in hydroponic systems (Resh 2013), assessment of bacterial and fungal diversity demonstrated that both treatments had similar effects on diversity indices (richness, ShannonWiener index, and evenness index). Other conditions, such as nutrients, temperature, and light, may maintain the same profile of bacterial and fungal community composition in these groups. In contrast, $P$. chlororaphis inoculation significantly altered bacterial and fungal diversity in hydroponic systems. Several studies demonstrated that PGPR (Bacillus spp.) play an important role in maintaining microbial populations and diversity in the rhizosphere (Kang et al. 2013). In the current study, the diversity index (richness, Shannon-Wiener, and evenness) of bacteria and fungi were altered by beneficial bacterial treatment. Introduction of $P$. chlororaphis has the powerful ability to control the bacterial and fungal diversity and structure in hydroponic systems.

In hydroponic cultivation, massive biofilm build-up is a nuisance problem and often interferes with system operation (Resh 2013; Schwartz et al. 2003). Our previous research showed that UV irradiation of the water reservoir is a useful solution to minimize biofilm build-up in vertical hydroponic systems, while sustaining a concentration of beneficial bacteria (P. chlororaphis) around the root area (Lee et al. 2015). Therefore, UV irradiation in the water reservoirs could extend the lifespan of a hydroponic system. In this study, we endeavored to understand the effect of UV irradiation on bacterial and fungal community structure and their diversity in water reservoirs, to clarify the effect of UV irradiation on bacterial and fungal ecology in hydroponic systems. The results of this study demonstrate that, in the water reservoir, the diversity of bacteria and fungi were significantly decreased and the community structure was altered by UV irradiation but this did not occur in the root areas.

\section{Bacterial and fungal identification.}

Microbial identification has provided opportunities to monitor microbial communities and their development in the systems. It also provides an insight into the probable relationships between microorganisms and plants (Fontana et al. 2005). Soil microbial community structure can be shaped by environmental conditions and plant types that interact with host plant (el Zahar Haichar et al. 2008). Observed results in this study may provide potential evidence that the presence of PGPR may manipulate plant development, enhance availability of nutrients, and act as biocontrol agents. Also, potential plant diseases interact with plants and compete with other microorganisms, including PGPR.

In conclusion, this research shows that introduction of beneficial bacteria in hydroponic systems enhances lettuce development and resistance to phytopathogens. This is the first report of bacterial and fungal diversity and community structure and transcriptomes of vegetables that are affected by beneficial bacteria in windowfarm hydroponic systems. Community change analysis showed that $P$. chlororaphis can be the most significant factor affecting bacterial and fungal diversity and community structure in both root area and circulating water in hydroponic systems. Transcriptomic analysis of lettuce following the $P$. chlororaphis treatment provided evidence for the overall effects of $P$. chlororaphis on lettuce, including triggering of defense mechanisms and metabolic pathways affecting lettuce development. The outcome of the study provides important knowledge about the relationship between plants and PGPR in hydroponic systems and, thus, contributes to improving controlled agriculture for protecting plants against diseases and enhancing their productivity.

\section{MATERIALS AND METHODS}

\section{Sample preparation.}

Windowfarm hydroponic systems were constructed for growing romaine lettuce (Fig. 1). A brief flowchart of the study design $(2 \times 2 \times 2$ factorial design) for all the hydroponic experiments, including the initial stages of romaine lettuce production is shown in Figure 2. The materials and methods of operation of the windowfarm, the growing conditions, the conditions of UV irradiation, and inoculum concentration of $P$. chlororaphis were previously described in detail (Lee et al. 2015). Briefly, during the 10-week experimental period, romaine lettuce (Lactuca sativa $\mathrm{L}$. var. longifolia) (Broomfield, CO, U.S.A.) was cultivated at 22 to $27^{\circ} \mathrm{C}$ and 30 to $47 \%$ relative humidity, using laboratory hydroponic systems at The Ohio State University (Columbus, $\mathrm{OH}$, U.S.A.). Each pot was packed with either $80 \mathrm{~g}$ of sterile clay pellets as supporting media (10 $\mathrm{mm}$ in diameter) (Easy Green Hydroton; Georg Buchner, Eschborn, Germany) or $80 \mathrm{~g}$ of a sterile 1:1 mixture of both the same clay pellets and glass beads $(5 \mathrm{~mm}$ in diameter) (glass beads solid, Fisher Scientific Inc., Waltham, MA, U.S.A.). Nutrients (132 $\mathrm{ml}$ per 100 liters of water with a nitrogen/phosphorus/potassium ratio of $2: 1: 6$; Botanicare Pro Grow Nutrients, Chandler, AZ, U.S.A.) were added to the water reservoir and nutrient solution was refilled every week. P. chlororaphis (ATCC 9446) was cultivated in tryptic soy broth 
(Becton Dickinson, Sparks, MD, U.S.A.) for $24 \mathrm{~h}$ at $28^{\circ} \mathrm{C}$ with shaking $(180 \mathrm{rpm})$. Approximately $1.0 \times 10^{8} \mathrm{CFU} / \mathrm{ml}$ of $P$. chlororaphis was inoculated around the root area two weeks after germination and, then, twice more (once a week) to enhance colonization of $P$. chlororaphis around root areas. A 254nm UV system (Atlantic Ultraviolet Co., Hauppauge, NY, U.S.A.) was used to inhibit nuisance biofilm buildup and algal growth in the water circulation system of the hydroponic systems and a mean intensity of $48 \mathrm{~W} / \mathrm{m}^{2}$ was applied to the water reservoir (at room temperature) once a week for $5 \mathrm{~min}$. There were eight different groups per test condition (Fig. 2). Each group had 24 replicates of romaine lettuce. After the lettuce was harvested, crop productivity (length and weight) were measured. To identify the difference between the productivity data in each group, data were analyzed using IBM SPSS Statistics 22 (SPSS, Inc., Chicago) by two-way analysis of variance with the Levene's test for homogeneity of variances that all the groups have succeeded in the normality test $(P>0.05)$. When $P$ value was less than 0.05 , there were significant differences. Transcriptomic analysis of lettuce from the control (group 1), P. chlororaphis-treated group (group 2), and P. chlororaphistreated group with UV irradiation (group 4) was conducted based on previous research in which we found no significant differences in lettuce color and productivity with different supporting media. To analyze bacterial and fungal communities, 16 different samples were collected, including eight supporting media samples from each group and eight water samples from a water reservoir of each group in the eight different hydroponic systems.

\section{Whole genome transcriptomic profiling.}

The lettuce leaves were sampled from the treated and control plants, were frozen immediately in liquid nitrogen at 3 days posttreatment, and were stored at $-80^{\circ} \mathrm{C}$ until RNA extraction. Total RNA was separately isolated from each leaf sample with the Totally RNA kit (Ambion, Austin, TX, U.S.A.), following the manufacturer's protocol. The isolated RNAs were treated with DNase I (Invitrogen, San Diego, CA, U.S.A.) to eliminate possible traces of genomic DNA contamination. RNA quality and quantity was examined by capillary electrophoresis on an Agilent Bioanalyzer 2100 (Agilent Technologies, Santa Clara, CA, U.S.A.). Only the RNA samples with $28 \mathrm{~S} / 18 \mathrm{~S}$ ratios in the range from 1.8 to 2.0 and RNA integrity index from 8.0 to 10.0 were selected for further processing. Three RNA samples separately prepared from each control or treated plant were used for RNA-Seq analysis. RNA-Seq library construction and sequencing were carried out in the Molecular and Cellular Imaging Center at The Ohio State University. Briefly, cDNA libraries were prepared with $6 \mu \mathrm{g}$ of starting total RNA, using the Illumina TruSeq RNA library prep kit according to the manufacturer's instructions. The libraries were enriched by 15 cycles of PCR with the TruSeq paired-end indexes, and the products with the desired size range were purified through $8 \%$ polyacrylamide gel electrophoresis. The purified cDNAs were checked again on the Agilent Bioanalyzer and were diluted to the suitable concentration for final Illumina sequencing on an Illumina HiSeq 2000 system with 100-bp paired-end reads.

To analyze transcriptomic data, RNA-Seq data were processed in the CLC Genomics Workbench 7.0 (CLC Bio, Aarhus, Denmark). The raw Illumina reads were trimmed to remove adapter sequences, ambiguous nucleotides (' $N$ ' at the end of reads), low quality sequences (scores less than 20), and short sequences (length below 30 base pairs). The resulting high-quality reads were used for the subsequent analyses: number of reads [\% perfect index reads]-control group, 6,770 Mbases [82.51\%]; UV irradiation group, 5,405 Mbases [81.56\%]; and $P$. chlororaphis treatment with UV irradiation group, 6,201 Mbases [82.79\%]. The reads were de novo assembled into contigs with a minimum size of 300 nucleotides to build a reference for the lettuce transcriptomes. The assembled contigs were queried for BLASTX searches against the NCBI Ref-Seq protein database (plant division) with an E-value cutoff of 1e-5. The top hits were parsed into an Excel file for further analysis. Afterward, GO annotation analysis was carried out, using the BLAST results in a Blast2GO program. The final annotation output was produced after gene ID mapping, GO term assignment, annotation augmentation, and generic GO-Slim processes. The annotation results were then analyzed with respect to cellular component, biological process, and molecular function, as reported in other CLCtranscriptomic analyses ( $\mathrm{Li}$ et al. 2012; Sun et al. 2012). The annotated contigs were used as a reference for comparative gene expression analysis. The high quality reads from each sample were mapped back against the reference contigs with a $95 \%$ similarity setup for loyal alignment to evaluate the gene expression levels. The expression levels were normalized to RPKM for identification of differentially expressed genes between the control and treated plants through the Kal's $Z$ test with a cutoff of 0.05 for false discovery rate-corrected $P$ value and 2.0 for fold changes.

\section{DNA extraction.}

Ten grams of each supporting media sample were mixed with $100 \mathrm{ml}$ of phosphate-buffered saline (Fisher Scientific). To isolate bacteria and fungi from the supporting media, samples were shaken for $10 \mathrm{~min}$, using a vortex mixer (Maxi Mix II; Barnstead/Thermolyne, Dubuque, IA, U.S.A.) and were then held for $2 \mathrm{~h}$ at room temperature in an incubator shaker (200 rpm) (New Brunswick Scientific Co., Inc., Edison, NJ, U.S.A.). After removing the beads using centrifugation at $3,500 \times \mathrm{g}$ for $5 \mathrm{~min}$ (CL2 centrifuge; Thermo Scientific, Hudson, NH, U.S.A.), $50 \mathrm{ml}$ of supernatant solution was collected. From all the water reservoirs, 100-ml water samples were also collected to prepare DNA extraction for bacterial and fungal community analysis. A total of $50 \mathrm{ml}$, each, of the cell solution from the beads and each water sample were mixed and prefiltered through a sterile $20-\mu \mathrm{m}$ pore size nylon filter membrane (Osmonics, Minnetonka, MN, U.S.A.) to remove large debris and were then filtered through a sterile 0.45 - $\mu \mathrm{m}$ pore size membrane filter (Isopore Membrane filters, Millipore, Cork, Ireland). The membranes were transferred into a 2-ml sterile tube, followed by the addition of $1.4 \mathrm{ml}$ of ASL buffer in the QIAamp DNA stool kit (Qiagen, Valencia, CA. U.S.A.), and 0.1 and $0.5 \mathrm{~mm}$ diameter autoclaved glass beads (Biospec Products, Bartlesville, OK, U.S.A.). Beadbeating was performed using a Mini-Beadbeater-96 (Biospec Products) at 2,100 oscillations per minute for $3 \mathrm{~min}$. The supernatant was transferred and the remaining DNA extraction process was performed using a QIAamp DNA stool kit, according to the manufacturer's instructions. The eluents were quantified for DNA concentration using a Qubit Fluorometer (Invitrogen). The DNA extracts were stored at $-80^{\circ} \mathrm{C}$ until they were analyzed.

\section{PCR amplification.}

The basic experimental design for bacterial diversity and community followed that of previous research (Ge et al. 2012). The primers (200-bp fragment of 16S rRNA gene of the V3 region) and volume of the PCR reaction were the same as described by Ge et al. (2012). To analyze diversity and community of fungi and oomycetes, the current research followed the protocol of Gao et al. (2012). However, from here on in this paper, we simply name the community and diversity of both fungi and oomycetes as 'fungal' community or diversity for convenience. For amplification of fungal sequences, two primers of $18 \mathrm{~S}$ rRNA regions were selected. PCR amplification was conducted using a MultiGene Thermal Cycler (Labnet, Edison, NY, U.S.A.). The PCR products were confirmed by agarose gel $(1.0 \% \mathrm{wt} / \mathrm{vol})$ electrophoresis and the gel was stained using ethidium bromide. 


\section{DGGE.}

The amplified PCR products were run in a DCode System (Bio-Rad, Hercules, CA, U.S.A.) with an $8 \%$ (wt/vol) polyacrylamide (37.5:1) gel. For bacterial diversity and community analysis, a denaturing gradient gel containing a 30 to $70 \%$ denaturing gradient was used and the electrophoresis was run at $60^{\circ} \mathrm{C}$ for $18 \mathrm{~h}$. For fungal diversity and community analysis, the denaturing gradient was 25 to $45 \%$ and the electrophoresis was at $60^{\circ} \mathrm{C}$ for $16 \mathrm{~h}$. The final gel images were captured using the Molecular Imager Gel Doc XR System (Bio-Rad). The DGGE band profiles were compared using BioNumerics software (version 7.10, Biosystematica, Tavistock, Devon, U.K.) as described by Hovda et al. (2007). Reference samples were loaded in the first and last lanes of each DGGE gel.

The obtained DGGE pattern images were subsequently normalized to correct any gel smiling or uneven band migration by comparison with two external reference lanes. The DGGE bands were selected using the band-searching algorithm of BioNumerics software (version 7.10, Biosystematica). After normalization of the gel images, only those bands with a peak height intensity exceeding $2.0 \%$ of the strongest band in each lane (lanes 1 to 16) were selected for further analyses. DGGE band data were used to examine biological diversity using two equations: the Shannon-Wiener index, $\mathrm{H}=-\sum \mathrm{P}_{\mathrm{i}} \ln \left(\mathrm{P}_{\mathrm{i}}\right)$ (Shannon and Weaver 1963; Yu and Morrison 2004) and the evenness index, $\mathrm{E}=\mathrm{H}^{\prime} / \mathrm{lnS}$ (Pielou 1966; Yu and Morrison 2004). Each band was treated as an individual operational taxonomic unit, where $S$ (richness) is the total number of DGGE bands in each lane, $\mathrm{P}_{\mathrm{i}}$ is the probability of the bands in each lane that is calculated from $n_{i} / N$ (where $n_{i}$ is the peak height of a band, and $\mathrm{N}$ is the sum of all peak heights in the curve of a given sample). The experimental data of the microbial diversity indices (Table 1) were analyzed using SPSS 17.0 statistical software (SPSS Inc.). The comparison of diversity indices between groups was performed using an independent two-sample $t$ test. Results were considered significant at $P<0.05$. To identify microbial similarity of the DGGE banding profiles, a dendrogram comparing samples was obtained using Pearson's coefficient and the neighbor-joining algorithm.

\section{Sequencing analysis of selected DGGE bands.}

The unique bands were excised from the gel using a sterile blade under UV transillumination and were placed into $30 \mu \mathrm{l}$, each, of nuclease-free water at $4^{\circ} \mathrm{C}$ for $24 \mathrm{~h}$. A total of $3 \mu \mathrm{l}$ of the supernatant were used as the template for PCR reamplification, under the same conditions as described earlier. After confirmation with $1.0 \%$ agarose gel electrophoresis, the PCR products were purified with a QIA quick PCR purification kit (Qiagen). The PCR products were sequenced using an ABI Prism 3730 DNA analyzer (Applied Biosystems, Foster City, CA, U.S.A.) in the Plant-Microbes Genomics Facility at The Ohio State University. The sequences were examined with a Sequence Scanner v1.0 (Applied Biosystems) to check for accuracy, and their taxonomic identification was determined by comparison with reference sequences in the GenBank database, using the BLAST search program.

\section{ACKNOWLEDGMENTS}

This study was partially supported by the Food Innovation Center at The Ohio State University. The authors thank Q. Sun and L. Wang for their technical assistance and $\mathrm{H}$. Kim for her contribution in constructing the figures.

\section{LITERATURE CITED}

Achard, P., Herr, A., Baulcombe, D. C., and Harberd, N. P. 2004. Modulation of floral development by a gibberellin-regulated microRNA. Development 131:3357-3365.
Alegria Terrazas, R., Giles, C., Paterson, E., Robertson-Albertyn, S., Cesco, S. Mimmo, T., Pii, Y., and Bulgarelli, D. 2016. Plant-microbiota interactions as a driver of the mineral turnover in the rhizosphere. Adv. Appl. Microbiol. 95:1-67.

Bargmann, B. O., and Munnik, T. 2006. The role of phospholipase D in plant stress responses. Curr. Opin. Plant Biol. 9:515-522.

Chérif, M., Tirilly, Y., and Bélanger, R. R. 1997. Effect of oxygen concentration on plant growth, lipidperoxidation, and receptivity of tomato roots to Pythium F under hydroponic conditions. Eur. J. Plant Pathol. 103:255.

Chin-A-Woeng, T. F. C., Bloemberg, G. V., Mulders, I. H. M., Dekkers, L. C., and Lugtenberg, B. J. J. 2000. Root colonization by phenazine1-carboxamide-producing bacterium Pseudomonas chlororaphis PCL1391 is essential for biocontrol of tomato foot and root rot. Mol. Plant-Microbe Interact 13:1340-1345.

Choudhary, D. K., and Johri, B. N. 2009. Interactions of Bacillus spp. and plants-With special reference to induced systemic resistance (ISR). Microbiol. Res. 164:493-513.

Demirevska-Kepova, K., Hölzer, R., Simova-Stoilova, L., and Feller, U. 2005 Heat stress effects on ribulose-1,5-bisphosphate carboxylase/oxygenase, Rubisco binding protein and Rubisco activase in wheat leaves. Biol. Plant 49:521-525.

el Zahar Haichar, F. Z., Marol, C., Berge, O., Rangel-Castro, J. I., Prosser, J. I., Balesdent, J., Heulin, T., and Achouak, W. 2008. Plant host habitat and root exudates shape soil bacterial community structure. ISME J. 2: 1221-1230.

Fontana, C., Vignolo, G., and Cocconcelli, P. S. 2005. PCR-DGGE analysis for the identification of microbial populations from Argentinean dry fermented sausages. J. Microbiol. Methods 63:254-263.

Gao, G., Yin, D., Chen, S., Xia, F., Yang, J., Li, Q., and Wang, W. 2012. Effect of biocontrol agent Pseudomonas fluorescens 2P24 on soil fungal community in cucumber rhizosphere using T-RFLP and DGGE. PLoS One 7:e31806.

Ge, C., Lee, C. S., Yu, Z., and Lee, J. 2012. Comparison of bacterial profiles of fish between storage conditions at retails using DGGE and banding pattern analysis: Consumer's perspective. Food Nutr. Sci. 3:190-200.

Germida, J., and Siciliano, S. 2001. Taxonomic diversity of bacteria associated with the roots of modern, recent and ancient wheat cultivars. Biol. Fertil. Soils 33:410-415.

Gül, A., Özaktan, H., Kıdoğlu, F., and Tüzel, Y. 2013. Rhizobacteria promoted yield of cucumber plants grown in perlite under Fusarium wilt stress. Sci. Hortic. (Amsterdam) 153:22-25.

Gul, A., Ozaktan, H., Yolageldi, L., Cakir, B., Sahin, M., and Akat, S. 2012 Effect of rhizobacteria on yield of hydroponically grown tomato plants. Acta Hortic. 952: 777-784.

Hegeman, C. E., Good, L. L., and Grabau, E. A. 2001. Expression of D-myoinositol-3-phosphate synthase in soybean. Implications for phytic acid biosynthesis. Plant Physiol. 125:1941-1948.

Hovda, M. B., Lunestad, B. T., Sivertsvik, M., and Rosnes, J. T. 2007. Characterisation of the bacterial flora of modified atmosphere packaged farmed Atlantic cod (Gadus morhua) by PCR-DGGE of conserved 16S rRNA gene regions. Int. J. Food Microbiol. 117:68-75.

Islam, F., Yasmeen, T., Ali, Q., Ali, S., Arif, M. S., Hussain, S., and Rizvi, H. 2014. Influence of Pseudomonas aeruginosa as PGPR on oxidative stress tolerance in wheat under Zn stress. Ecotoxicol. Environ. Saf. 104: 285-293.

Iuchi, S., Kobayashi, M., Yamaguchi-Shinozaki, K., and Shinozaki, K. 2000. A stress-inducible gene for 9-cis-epoxycarotenoid dioxygenase involved in abscisic acid biosynthesis under water stress in droughttolerant cowpea. Plant Physiol. 123:553-562.

Jones, D. A., and Jones, J. D. G. 1997. The role of leucine-rich repeat proteins in plant defences. Adv. Bot. Res. 24:90-168.

Jones, J. B. 1997. Hydroponics: A practical guide for the soilless grower St. Lucie Press, Boca Raton, FL, U.S.A.

Kang, Y., Shen, M., Wang, H., and Zhao, Q. 2013. A possible mechanism of action of plant growth-promoting rhizobacteria (PGPR) strain Bacillus pumilus WP8 via regulation of soil bacterial community structure. J. Gen. Appl. Microbiol. 59:267-277.

Khan, A., Sutton, J. C., and Grodzinski, B. 2003. Effects of Pseudomonas chlororaphis on Pythium aphanidermatum and root rot in peppers grown in small-scale hydroponic troughs. Biocontrol Sci. Technol. 13:615-630.

Koseki, S., Mizuno, Y., and Yamamoto, K. 2011. Comparison of two possible routes of pathogen contamination of spinach leaves in a hydroponic cultivation system. J. Food Prot. 74:1536-1542.

Lakshmanan, V., Castaneda, R., Rudrappa, T., and Bais, H. P. 2013. Root transcriptome analysis of Arabidopsis thaliana exposed to beneficial Bacillus subtilis FB17 rhizobacteria revealed genes for bacterial recruitment and plant defense independent of malate efflux. Planta 238:657-668 
Lee, S., Ge, C., Bohrerova, Z., Grewal, P. S., and Lee, J. 2015. Enhancing plant productivity while suppressing biofilm growth in a windowfarm system using beneficial bacteria and ultraviolet irradiation. Can. J. Microbiol. 61:457-466.

Li, H., Pinot, F., Sauveplane, V., Werck-Reichhart, D., Diehl, P., Schreiber, L., Franke, R., Zhang, P., Chen, L., Gao, Y., Liang, W., and Zhang, D. 2010. Cytochrome P450 family member CYP704B2 catalyzes the $\omega$-hydroxylation of fatty acids and is required for anther cutin biosynthesis and pollen exine formation in rice. Plant Cell 22:173-190.

Li, J., Dai, X., and Zhao, Y. 2006. A role for auxin response factor 19 in auxin and ethylene signaling in Arabidopsis. Plant Physiol. 140:899-908.

Li, L., Zhao, Y., McCaig, B. C., Wingerd, B. A., Wang, J., Whalon, M. E., Pichersky, E., and Howe, G. A. 2004. The tomato homolog of CORONATINE-INSENSITIVE1 is required for the maternal control of seed maturation, jasmonate-signaled defense responses, and glandular trichome development. Plant Cell 16:126-143.

Li, M., Cheung, V. G., and Wang, I. X. 2012. Response to comments on "Widespread RNA and DNA sequence differences in the human transcriptome". Science 335:1302.

Narendra, S., Venkataramani, S., Shen, G., Wang, J., Pasapula, V., Lin, Y., Kornyeyev, D., Holaday, A. S., and Zhang, H. 2006. The Arabidopsis ascorbate peroxidase 3 is a peroxisomal membrane-bound antioxidant enzyme and is dispensable for Arabidopsis growth and development. J. Exp. Bot. 57:3033-3042.

Narusaka, Y., Narusaka, M., Seki, M., Umezawa, T., Ishida, J., Nakajima, M., Enju, A., and Shinozaki, K. 2004. Crosstalk in the responses to abiotic and biotic stresses in Arabidopsis: Analysis of gene expression in cytochrome P450 gene superfamily by cDNA microarray. Plant Mol. Biol. 55:327-342.

Niewiadomski, P., Knappe, S., Geimer, S., Fischer, K., Schulz, B., Unte, U. S., Rosso, M. G., Ache, P., Flügge, U. I., and Schneider, A. 2005. The Arabidopsis plastidic glucose 6-phosphate/phosphate translocator GPT1 is essential for pollen maturation and embryo sac development. Plant Cell 17:760-775

Nonomura, T., Tajima, H., Kitagawa, Y., Sekiya, N., Shitomi, K., Tanaka, M., Maeda, K., Matsuda, Y., and Toyoda, H. 2003. Distinguishable staining with neutral red for GFP-marked and GFP-nonmarked Fusarium oxysporum strains simultaneously colonizing root surfaces. J. Gen. Plant Pathol. 69:45-48.

Park, J. H., Halitschke, R., Kim, H. B., Baldwin, I. T., Feldmann, K. A., and Feyereisen, R. 2002. A knock-out mutation in allene oxide synthase results in male sterility and defective wound signal transduction in Arabidopsis due to a block in jasmonic acid biosynthesis. Plant J. 31:1-12.

Parray, J. A., Jan, S., Kamili, A. N., Qadri, R. A., Egamberdieva, D., and Ahmad, P. 2016. Current perspectives on plant growth-promoting rhizobacteria. J. Plant Growth Regul. 35:877-902.

Peer, R., and Schippers, B. 1989. Plant growth responses to bacterization with selected Pseudomonas spp. strains and rhizosphere microbial development in hydroponic cultures. Can. J. Microbiol. 35:456-463.

Pielou, E. C. 1966. The measurement of diversity in different types of biological collections. J. Theor. Biol. 13:131-144.

Pii, Y., Borruso, L., Brusetti, L., Crecchio, C., Cesco, S., and Mimmo, T. 2016a. The interaction between iron nutrition, plant species and soil type shapes the rhizosphere microbiome. Plant Physiol. Biochem. 99:39-48.

Pii, Y., Marastoni, L., Springeth, C., Fontanella, M. C., Beone, G. M., Cesco, S., and Mimmo, T. 2016b. Modulation of Fe acquisition process by Azospirillum brasilense in cucumber plants. Environ. Exp. Bot. 130:216-225.

Pii, Y., Mimmo, T., Tomasi, N., Terzano, R., Cesco, S., and Crecchio, C. 2015. Microbial interactions in the rhizosphere: Beneficial influences of plant growth-promoting rhizobacteria on nutrient acquisition process. A review. Biol. Fertil. Soils 51:403-415.

Pii, Y., Molesini, B., Masiero, S., and Pandolfini, T. 2012. The non-specific lipid transfer protein N5 of Medicago truncatula is implicated in epidermal stages of rhizobium-host interaction. BMC Plant Biol. 12:233.

Piromyou, P., Buranabanyat, B., Tantasawat, P., Tittabutr, P., Boonkerd, N., and Teaumroong, N. 2011. Effect of plant growth promoting rhizobacteria (PGPR) inoculation on microbial community structure in rhizosphere of forage corn cultivated in Thailand. Eur. J. Soil Biol. 47:44-54.

Resh, H. M. 2013. Hydroponic food production: A definitive guidebook for the advanced home gardener and the commercial hydroponic grower. CRC Press, Boca Raton, Fla.
Reumann, S., Babujee, L., Ma, C., Wienkoop, S., Siemsen, T., Antonicelli, G. E., Rasche, N., Lüder, F., Weckwerth, W., and Jahn, O. 2007. Proteome analysis of Arabidopsis leaf peroxisomes reveals novel targeting peptides, metabolic pathways, and defense mechanisms. Plant Cell 19:3170-3193.

Scagliola, M., Pii, Y., Mimmo, T., Cesco, S., Ricciuti, P., and Crecchio, C. 2016. Characterization of plant growth promoting traits of bacterial isolates from the rhizosphere of barley (Hordeum vulgare L.) and tomato (Solanum lycopersicon L.) grown under Fe sufficiency and deficiency. Plant Physiol. Biochem. 107:187-196.

Schönwitz, R., and Ziegler, H. 1986. Quantitative and qualitative aspects of a developing rhizosphere microflora of hydroponically grown maize seedlings. J. Plant Nutr. Soil Sci. 149:623-634.

Schwartz, T., Hoffmann, S., and Obst, U. 2003. Formation of natural biofilms during chlorine dioxide and u.v. disinfection in a public drinking water distribution system. J. Appl. Microbiol. 95:591-601.

Shannon, C. E., and Weaver, W. 1963. The mathematical theory of communication. University of Illinois Press, Urbana.

Shih, M., Hoekstra, F., and Hsing, Y. C. 2008. Late embryogenesis abundant proteins. Adv. Bot. Res. 48:211-255.

Smalla, K., Wieland, G., Buchner, A., Zock, A., Parzy, J., Kaiser, S., Roskot, N., Heuer, H., and Berg, G. 2001. Bulk and rhizosphere soil bacterial communities studied by denaturing gradient gel electrophoresis: Plant-dependent enrichment and seasonal shifts revealed. Appl. Environ. Microbiol. 67:4742-4751.

Sun, J., Wang, M., Wang, H., Zhang, H., Zhang, X., Thiyagarajan, V., Qian, P. Y., and Qiu, J. W. 2012. De novo assembly of the transcriptome of an invasive snail and its multiple ecological applications. Mol. Ecol. Resour. 12:1133-1144.

van Os, E. A., Amsing, J. J., van Kuik, A. J., and Willers, H. 1999. Slow sand filtration: A potential method for the elimination of pathogens and nematodes in recirculating nutrient solutions from glasshouse-grown crops. Acta Hortic. 481: 519-526.

Verhagen, B. W., Glazebrook, J., Zhu, T., Chang, H. S., van Loon, L. C., and Pieterse, C. M. 2004. The transcriptome of rhizobacteria-induced systemic resistance in arabidopsis. Mol. Plant-Microbe Interact 17:895-908.

Walker, R., Powell, A. A., and Seddon, B. 1998. Bacillus isolates from the spermosphere of peas and dwarf French beans with antifungal activity against Botrytis cinerea and Pythium species. J. Appl. Microbiol. 84:791-801.

Wallace, R. J., Jr., Meier, A., Brown, B. A., Zhang, Y., Sander, P., Onyi, G. O., and Böttger, E. C. 1996. Genetic basis for clarithromycin resistance among isolates of Mycobacterium chelonae and Mycobacterium abscessus. Antimicrob. Agents Chemother. 40:1676-1681.

Wasternack, C., Stenzel, I., Hause, B., Hause, G., Kutter, C., Maucher, H., Neumerkel, J., Feussner, I., and Miersch, O. 2006. The wound response in tomato-Role of jasmonic acid. J. Plant Physiol. 163:297-306.

Wechter, W. P., Levi, A., Harris, K. R., Davis, A. R., Fei, Z., Katzir, N., Giovannoni, J. J., Salman-Minkov, A., Hernandez, A., Thimmapuram, J., Tadmor, Y., Portnoy, V., and Trebitsh, T. 2008. Gene expression in developing watermelon fruit. BMC Genomics 9:275.

Xiao, H., Cheng, S., and Wu, Z. 2010. Microbial community variation in phytoremediation of triazophos by Canna indica Linn. in a hydroponic system. J. Environ. Sci. (China) 22:1225-1231.

Yu, J., Zhou, X. F., Yang, S. J., Liu, W. H., and Hu, X. F. 2013. Design and application of specific 16S rDNA-targeted primers for assessing endophytic diversity in Dendrobium officinale using nested PCR-DGGE. Appl. Microbiol. Biotechnol. 97:9825-9836.

Yu, Z., and Morrison, M. 2004. Comparisons of different hypervariable regions of $r r s$ genes for use in fingerprinting of microbial communities by PCR-denaturing gradient gel electrophoresis. Appl. Environ. Microbiol. 70:4800-4806.

Zheng, J., Sutton, J. C., and Yu, H. 2000. Interactions among Pythium aphanidermatum, roots, root mucilage, and microbial agents in hydroponic cucumbers. Can. J. Plant Pathol. 22:368-379.

\section{AUTHOR-RECOMMEDED INTERNET RESOURCES}

Blast2GO website: https://www.blast2go.com/home

The Plant-Microbes Genomics Facility at The Ohio State University: http://pmgf.osu.edu 